\title{
Energy-Saving Behaviour of Households: Methodological Aspects of Research
}

\author{
Rais Burganov ${ }^{1, *}$, Eltna Dolonona ${ }^{1}$, Lilia Urasbahtina ${ }^{1}$ \\ ${ }^{1}$ Kazan State Power Engineering University, Department of Economics and Organization of Production, Krasnoselskaya Str. 51, \\ Kazan, 420066, Russia
}

\begin{abstract}
The paper deals with the theoretical and methodological aspects of studying and modelling energy-saving behaviour of households in modern conditions. The main goal is to provide the scientific community in a concise form with these research results concerning the methodological support for the theoretical study of problems related to energy-saving behaviour of households. Extended version of the study on this topic will be published in a20003@mail.vstecb.cz different format. Scientific research methods are based on the use of abstraction and systematization of these energy-saving processes in households, the use of the principle "all other things being equal", and the study of official statistical materials. The theoretical basis was the teachings of representatives of institutionalism and the neoclassical direction of economic theory. The obtained results include a conclusion about the features of modelling energy saving of households, which should be taken into account when preparing practical recommendations in the field of energy consumption; on the criteria for modelling based on the grouping of households and the types of their behaviour in the field of energy saving. The fundamental variables in obtaining the effect of energy saving are the processes of organizing and self-organizing the process of energy consumption by households, which make it possible to apply effective energy-saving actions. Also, in the final part of the work, a system of variable factors influencing the energy consumption of households and used in modelling their behaviour is presented. The advantage of the study is that, for the first time in a systematic way, the theoretical and methodological aspects of studying the behaviour of households in energy saving are considered, which will allow obtaining a holistic view of trends in energy consumption. An in-depth study of the scientific foundations of the process of energy conservation in households can contribute to the formation of effective government and business programs and thereby rationalize the behaviour of households as consumers and suppliers of energy resources.
\end{abstract}

Keywords: household behaviour; energy saving; organizational behaviour; institutional infrastructure in energy saving

\section{Introduction}

All subjects of the national economy are interested in energy saving. However, in the main focus of the state bodies responsible for reducing the energy intensity of production are state institutions, branches of the national economy, and large economic units. The problems in the formation of energy-saving behaviour at the household level remain in the background. This is despite the fact that in the world and in individual countries there is an increase in energy consumption by households. However, the absence of a holistic and systematic approach to the study of the behaviour of households' energy saving does not allow making the correct strategic management decision, both at the state level and at the level of the households themselves. The need to study the behavioural aspects of household behaviour in energy conservation is a modern requirement. For example, the Global Commission on Urgent Action on Energy Efficiency following a conference at the International Energy Agency (IEA) recommended: "Use behavioural insights for more effective policies. People are at the centre of energy efficiency efforts, and understanding the behavioural sciences can help design smarter policies" [1]. However, in order to obtain real results in this area, it is necessary to determine the theoretical and methodological basis for studying the behaviour of consumers of energy of any kind. As hypotheses, one can propose the existence of significant differences between the positions of different theories regarding the study of the behaviour of households in energy saving (H1) and the multidimensionality of the processes of its manifestation $(\mathrm{H} 2)$.

\section{Methodology}

In order to obtain scientific results, an arsenal of methodology of economic theory was used; namely, the methods of generalization and abstraction, systematization, the principle of "other things being equal", as well as the study of official statistical materials on the research topic. The theoretical basis was the teachings of representatives of institutionalism

\footnotetext{
* Corresponding author: burraabr@gmail.com
} 
and the neoclassical direction of economic theory. As you know, at present, any action of market participants can be characterized in the form of models. In particular, situational modelling of household behaviour can be used. In this study, it is necessary to use a generalized model of household behaviour, which can be specified in the form of the following equation:

$$
\text { Energy saving = benefit + energy saving infrastructure + culture (1) }
$$

This kind of energy-saving model shows the need for a holistic solution to problems in the behaviour of the households, and requires taking into account all types of its manifestations.

In the scientific literature, you can find many publications devoted to the study of certain aspects of the behaviour of households in energy consumption.

Among the significant works of recent years, one can single out the studies of Boudet X. and others on the clustering of energy-saving behaviour in the family [2], Giovanni Frigo et al on the importance of individual energy consumption for human development and well-being [3], V. Strielkowski, in particular on the impact and scale of the penetration of renewable energy into households [4]. In Russian science, I. A. Bashmakov I. A., Bushuev V. V., and many others. In particular, one can note the article by I. A. Bashmakov on the need to improve the efficiency of energy use [5], and the fundamental work of V. V. Bushuev about the target vision of the energy sector of the future [6]. Certain aspects of the topic are considered in the writings of Burganov R. [7-8].

\section{Results and Discussion}

For the development of various models of energy-saving behaviour of households, all variables can be classified on different grounds; in particular, based on identifying key (significant) and non-key (insignificant) variables. Key (essential) variables predetermine the process of formation and development of the behaviour of the household in energy saving (Table 1).

Table 1. Model variables energy saving behaviour of households

\begin{tabular}{|l|l|l|}
\hline \multirow{2}{*}{$\begin{array}{l}\text { Scientific } \\
\text { foundations }\end{array}$} & \multicolumn{1}{|c|}{ Behaviour variables } \\
\cline { 2 - 3 } $\begin{array}{l}\text { Neoclassical } \\
\text { theory }\end{array}$ & $\begin{array}{l}\text { Key } \\
\text { Necessity (need) for energy } \\
\text { Renefits of energy consumption processes } \\
\text { Rnergy tariffs }\end{array}$ & $\begin{array}{l}|c| \\
\text { Elasticity } \\
\text { Energy tariffs }\end{array}$ \\
\hline $\begin{array}{l}\text { Institutional } \\
\text { theory }\end{array}$ & $\begin{array}{l}\text { Organizational, managerial, and institutional conditions } \\
\text { for energy consumption } \\
\text { The most important institution is a deal (contract) }\end{array}$ & $\begin{array}{l}\text { Socio-psychological factors } \\
\text { Emotional factors }\end{array}$ \\
\hline Keynesianism & $\begin{array}{l}\text { Part of ensuring reproduction } \\
\text { Household behaviour can influence GDP growth, } \\
\text { aggregate demand and supply. }\end{array}$ & $\begin{array}{l}\text { Productivity from the real sector } \\
\text { of the economy }\end{array}$ \\
\hline
\end{tabular}

Source: Authors.

As can be seen from the table, depending on the theoretical approaches, the key variables for modelling the energysaving behaviour of households differ.

In general, the process of the formation of energy-saving behaviour of households depends on the implementation of many scientific ideas within the framework of the main scientific directions of economic theory.

But, in order to obtain effective, efficient, and systemic solutions, it is necessary to pay attention to new approaches to the energy-saving process. In particular, in energy-saving processes, one can single out the organizational mechanisms of the behaviour of households.

In fact, the study of any phenomenon from the point of view of its organization is the starting point of the analysis. Organization is a systems approach based on coordinating the actions of households as energy consumers with energy suppliers. Organizational forms include the purposeful activity of households in the formation of behaviour in energy saving. Organizational forms also include the distribution of responsibilities among members of the household, effective placement, and use of energy-receiving and energy-producing devices and equipment, etc. Households should use organizational forms in energy consumption, and self-organize in the field of reducing energy consumption of any kind. 
Self-organization, i.e. the willingness of households to use technical and technological means (power receivers, control and measuring devices, etc.), to allocate astronomical time for control measures over the state of energy consumption, the implementation of contractual relations (for example, timely payment). Self-organization of households in energy saving can be defined as the orderly activities of households in a targeted impact on the optimization of energy consumption of any kind in order to meet their needs while creating favourable and comfortable living conditions. The process of self-organization is implemented more when living in private houses. According to Rosstat, more than $29 \%$ of Russians live in private houses, excluding summer houses and cottages. Self-organization in energy saving covers the organization of energy use for heating, air conditioning, hot water supply, cooking, lighting, household appliances, etc. The key elements of self-organization of households in energy saving as a system are the awareness of the state of energy consumption, the possibility of influencing the energy saving process, determining time periods for tracking the progress of energy saving, comparative analysis of energy saving data by periods of consumption, coordination of family members in behavioural actions, and the control of payment transactions for the energy used.

Also, the organizational form of the behaviour of households in energy conservation includes data management based on access to information about energy consumption using interactive services. The energy-saving behaviour of households based on data management, and the access to information on energy consumption using interactive services are important factors in the development of the energy market in the national economy.

In a mathematical model, the process of energy-saving behaviour of households can be described either by one or by many parametric representations. In a model with one parameter, one can take the growth of the population's income, which forms the energy-saving behaviour of energy users most significantly. In multi-parameter mathematical models, the influence of external (main and secondary) and internal (main and auxiliary) factors on the energy-saving behaviour of households is taken into account. Each variable can be positively or negatively reflected in the rational or irrational in the behaviour of households in energy saving (Table 2).

Table 2. Approximate classification of energy-saving factors in households

\begin{tabular}{|c|c|c|c|}
\hline № & Factors & Characteristic of factor (s) & Examples \\
\hline 1 & External & $\begin{array}{l}\text { Influencing the energy saving process } \\
\text { from outside the energy saving system }\end{array}$ & \\
\hline & including: & & \\
\hline 1.1 & main & $\begin{array}{l}\text { Defining goal and meaning of energy } \\
\text { saving }\end{array}$ & $\begin{array}{l}\text { The introduction of a tax on income } \\
\text { received as a result of energy saving }\end{array}$ \\
\hline 1.2 & minor & $\begin{array}{l}\text { Influencing the actions and } \\
\text { Interconnections of the elements of the } \\
\text { energy-saving system, }\end{array}$ & $\begin{array}{l}\text { The use of outdated house infrastructure } \\
\text { of energy networks }\end{array}$ \\
\hline 1.3 & ... etc. & & $\begin{array}{l}\text { Environment } \\
\text { The influence of the house committee }\end{array}$ \\
\hline \multirow[t]{2}{*}{2} & Internal & $\begin{array}{l}\text { Influencing the energy saving process } \\
\text { from within the energy saving system }\end{array}$ & \\
\hline & including: & & \\
\hline 2.1 & main & $\begin{array}{l}\text { Targets for Energy Saving of Family } \\
\text { Members }\end{array}$ & $\begin{array}{l}\text { Principle } \\
\text { "When leaving, turn off the light" }\end{array}$ \\
\hline 2.2 & auxiliary & $\begin{array}{l}\text { Level of equipment with energy-saving } \\
\text { devices }\end{array}$ & $\begin{array}{l}\text { The presence of energy receivers in the } \\
\text { household with the class "A +++" }\end{array}$ \\
\hline 2.3 & ... etc. & & $\begin{array}{l}\text { Energy literacy } \\
\text { Energy-saving culture }\end{array}$ \\
\hline
\end{tabular}

Source: Authors.

In addition, to obtain a comprehensive analysis of the energy-saving behaviour of households, it is necessary to group them into homogeneous elements, and then draw an appropriate conclusion. The criterion for grouping (homogeneity) can be different circumstances, for example, household income, social status, living space per family, type of residential building, provision of an apartment and/or a house with general household energy metering devices, etc. (Table 3). 
Table 3. Criteria for grouping households and types of their behaviour

\begin{tabular}{|c|c|c|}
\hline № & Grouping criteria & Type of behaviour \\
\hline $\begin{array}{l}1 \\
1.1 . \\
1.2 .\end{array}$ & $\begin{array}{l}\text { Income: } \\
\text { High income } \\
\text { Low income }\end{array}$ & $\begin{array}{l}\text { Wasteful, ostentatious (excessive) } \\
\text { consumption } \\
\text { Energy saving }\end{array}$ \\
\hline $\begin{array}{c}2 \\
2.1 \\
2.2 \\
2.3\end{array}$ & $\begin{array}{l}\text { Social status: } \\
\text { The head of the family is the leader } \\
\text { The head of the family is subordinate } \\
\text { The head of the family is non-working (pensioners, etc.) }\end{array}$ & $\begin{array}{l}\text { Calculating } \\
\text { Less calculating } \\
\text { Calculating }\end{array}$ \\
\hline $\begin{array}{c}3 \\
3.1 \\
3.2\end{array}$ & $\begin{array}{l}\text { Living space per head of residents } \\
\text { At the standard level } \\
\text { Above the standard }\end{array}$ & $\begin{array}{l}\text { Calculating } \\
\text { Less calculating }\end{array}$ \\
\hline $\begin{array}{c}4 \\
4.1 \\
4.2\end{array}$ & $\begin{array}{l}\text { Residing building type: } \\
\text { Class A + } \\
\text { Other classes }\end{array}$ & $\begin{array}{l}\text { Calculating } \\
\text { Less calculating }\end{array}$ \\
\hline $\begin{array}{l}5 \\
5.1 \\
5.2\end{array}$ & $\begin{array}{l}\text { The provision of an apartment and/or a house with general } \\
\text { house energy metering devices: } \\
\text { Secured } \\
\text { Unsecured }\end{array}$ & $\begin{array}{l}\text { Energy saving } \\
\text { Energy waste }\end{array}$ \\
\hline $\begin{array}{c}6 \\
6.1 \\
6.2 \\
\end{array}$ & $\begin{array}{l}\text { Education of family members } \\
\text { Higher education } \\
\text { Secondary education }\end{array}$ & $\begin{array}{l}\text { More energy saving } \\
\text { Less energy efficient }\end{array}$ \\
\hline 7 & Availability of energy competence & Energy saving \\
\hline
\end{tabular}

Source: Authors.

Of course, the selection of criteria for grouping households and their types of behaviour are incomplete and controversial. For example, according to social status, a large number of criteria can be distinguished.

The conditions and processes of saving energy are formalized in numerous legislative and regulatory documents of different levels. Only in Russia, at the federal level, over the past years, three state programs and three energy strategies have been created. However, the effectiveness and efficiency of implementations of the provisions of these documents is far from perfect. In particular, many of these provisions undergo adjustments and additions almost every year, as a result of which the level of confidence in these documents decreases. Timely payment for electricity use is perceived by many consumers as a norm of behaviour.

Of particular importance within the framework of institutional theory is the concept based on the use of a system of contracts and agreements. In particular, households in the field of energy supply can conclude such contracts as an agreement on the supply of electricity, on the provision of services for the development of a list of energy service activities; contract for the installation of energy service equipment; an agreement on the provision of services for the analysis and maintenance of energy service activities, etc. The process of concluding each agreement and energy contract has its own characteristics. Each type of agreement and energy contract includes costs incurred before its conclusion, during the process of conclusion, and after the conclusion.

In the studies of the founders of the course of institutionalism J. Commons, D. North, T. Veblen, W. Mitchell and others, as well as in the works of modern scientists, one can find many provisions suitable for analysing the behaviour of households in energy consumption and energy saving.

In modern studies, attention is paid to the consideration of new factors affecting the energy saving of households. For example, regarding property, more precisely, according to the economic theory of property rights. There are certain disagreements of interests regarding the consumption of electricity for the needs of households and for the maintenance of communal power grids. Common property is a significant consumer of electricity in apartment buildings; one of its aspects is discussed in the work of Moiz Masood Syed and his colleagues [9].

Establishing a rational relationship between family-wide and individual consumption of family members is a serious problem. Each family member can act in their own interests in energy consumption, which can cause a conflict about energy saving in the family circle.

Some aspects of the importance of individual energy consumption for human development and well-being are discussed in the work of Giovanni Frigo et al. [10].

Separate studies are devoted to the analysis of the influence of emotions on the possibility of reducing or increasing the volume of energy consumption. Saving energy depends on the mental and psychological state of each member of the household. In particular, in a joyful state, the consumer pays less attention to the need for energy saving. Revealing emotions through collective action and forms of social learning can lead to opportunities for transformative, socially embedded change — both reducing and improving energy use [11]. 
S of the impact of demographic evolution of households on their energy consumption should be also noted. This refers to the impact of the transition from one type of family to another (for example, from a single to a couple without children), which has not been studied previously [12]. The results of the study show that the evolution of households has a significant impact on their energy consumption patterns. However, the magnitude and direction of this effect are correspondingly weak and predominantly positive.

According to the institutional and technological concept, it is necessary for institutions to introduce the use of new energy-saving technologies and energy-receiving devices, for example class A +++, into the process of energy consumption of households. A number of works can be found, for example, the study of Brischke and his colleagues [13]; Zhang Y. and others [14].

A special role in energy saving is played by the moral and educational concept of institutionalism, according to which the behaviour of households depends on the functioning of such institutions as customs, traditions, and respect for energy and heat resources. The economic benefit expected from habit formation is a reduction in the costs associated with decision-making, observation, and/or trial and error (delusions) that would or could happen with less automatic behaviour [15].

Karlijn L. van den Broek provides an overview and organization of energy literacy, which focuses on understanding household electricity and gas use, providing a basis for classifying various conceptual and methodological approaches [16].

In general, modelling the process of saving energy in households based on the above factors is difficult and painstaking work and it is impossible to obtain real practical results without using modern methods of data analysis.

\section{Conclusion}

In conclusion, we can note the importance of a systematic theoretical study of the essence of the households behaviour in the field of energy conservation. Hypothesis H1 is confirmed. From the point of view of neoclassicists, that is, from the point of view of the "market", one can single out the desire of households to receive financial or other benefits based on the economic use of energy of any kind. The institutional characteristic of the energy-saving behaviour of households includes the creation of an appropriate infrastructure. When using different theoretical positions in the study of household behaviour, contradictory or even opposite results can be obtained. In particular, one can focus on obtaining only benefits due to energy savings, but the intention to invest in the installation of energy-saving technologies in the short term may not lead to its receipt.

According to the $\mathrm{H} 2$ hypothesis, it can be noted that the conditions and processes of energy saving are formalized in numerous legislative and regulatory documents of different levels, which indicates the multi-factor nature of obtaining an energy-saving effect in the behaviour of a household (Table 2). A comprehensive scientific direction is the study of the behaviour of households in the field of energy conservation based on the implementation of their organizational forms. Organizational forms include the distribution of responsibilities among family members, as well as the efficient placement of devices and equipment that receive and produce energy. Variables modelling household behaviour should group households according to different criteria. The criterion for grouping (homogeneity) can be various circumstances, for example, household income, social status, living space per family, type of residential building, provision of an apartment and/or a house with general house energy meters, etc.

In the context of the formation of a digital society and economy and the use of nature-like technologies in the energysaving behaviour of households, transformational changes are objectively taking place, which should be carried out flexibly, taking into account the level of preparedness for innovations of consumers of various types of energy.

A key factor in changing household behaviour is the use of digital technologies in the process of energy consumption of all types. The state should create a system of incentive measures in the field of the formation of rational household behaviour, including postponing an effective organizational mechanism "supply-pay" in energy supply.

\section{Acknowledgments}

The reported study was funded by RFBR, project number 20-010-00099 [A1] "Theoretical and methodological approaches to the development of models of energy-saving behaviour of households in a nature-like economy».

\section{References}

1. L. Varadkar. Recommendations of the Global Commission for Urgent Action on Energy Efficiency [online]. Available at: https://iea.blob.core.windows.net/assets/d40d5638-1f45-42ac-b072-fe9e6417cc1e/GlobalCommission-Recommendations.pdf (2020) 
2. H. S. Boudet, J. A. Flora, K. C. Armel. Clustering household energy-saving behaviours by behavioural attribute. Energy Policy. 92, 444-454 (2016).

3. G. Frigo, M. Baumann, R. Hillerbrand. Energy and the Good Life: Capabilities as the Foundation of the Right to Access Energy Services. Journal of Human Development and Capabilities. 22(2), 218-248 (2021)

4. V. Strielkowski, E. Volkova, L. Pushkareva, D. Streimikiene. Innovative Policies for Energy Efficiency and the Use of Renewables in Households. Energies. 12(7), 1392 doi:org/10.3390/en12071392 (2019)

5. V. Bashmakov. Improving energy efficiency and economic growth. Economic issues. 10, 32-63 (2019)

6. V. Bushuev. Energy of Russia (selected articles, reports, presentations of 2014-2018). Journal of Environmental Earth and Energy Study (JEEES). 5 (2018)

7. R. Burganov, E. Altynbaeva, L. Maimakova. Factor analysis of energy saving in households. E3S Web of Conferences. 209 doi:org/10.1051/e3sconf/202020903009 (2020)

8. R. Burganov, L. V. Maimakova, L. Urazbakhtina, L. A. Golitsyna. On the need to improve the methodology for calculating energy saving and energy efficiency of enterprises. IOP Conference Series Materials Science and Engineering. 791(1), 012040 (2020)

9. M. M. Syed, G. M. Morrison, J. Darbyshir. Energy Allocation Strategies for Common Property. Load Connected to Shared Solar and Battery Storage. Systems in Strata Apartments. Energies. 13(22), 6137 doi:org/10.3390/en13226137 (2020)

10. G. Frigo, M. Baumann, R. Hillerbrand. Energy and the Good Life: Capabilities as the Foundation of the Right to Access Energy Services. Journal of Human Development and Capabilities. 22(2), 218-248 (2021)

11. M. Sahakian, B. Bertho. Exploring emotions and norms around Swiss household energy usage: When methods inform understandings of the social. Energy Research \& Social Science. 45, 81-90 doi:org/10.1016/j.erss.2018.06.017 (2018)

12. M. L. Chalal, M. Benachir., M. White, G. Shahtahmassebi, R. Shrahily. A Comprehensive Study on the Effect of Households' Evolution on Residential Energy Consumption Patterns. Proceedings of 3rd International Sustainable Buildings Symposium (ISBS 2017). 6, 485-500 doi:org/10.1007/978-3-319-63709-9_39 (2018)

13. L. A. Brischke, F. Lehmann, L. Leuser, S. Thomas, C. Baedeker. Energy sufficiency in private households enabled by adequate appliances. Conference: ECEEE - Summer Study 2015. 1571-1582 (2015)

14. Z. Xin-Gang, M. Xin, Z.Ying, L. Pei-Ling. Policy inducement effect in energy efficiency: An empirical analysis of China. Energy. 211 doi:org/10.1016/j.energy.2020.118726/ (2020)

15. D. Coldwel. The Economics of Habits. Humboldt Journal of Social Relations. 8(2), 1-10 (1990)

16. K. van den Broek. Household energy literacy: A critical review and a conceptual typology Energy Research \& Social Science. 57(5) (2019) 